\title{
Amniotic membrane grafts, "fresh" or frozen? A clinical and in vitro comparison
}

\author{
Philip J Adds, Charles J Hunt, John K G Dart
}

\begin{abstract}
Backgroundlaims-The use of "fresh" (hypothermically stored) and frozen amniotic membrane (AM) was compared in a patient with cicatricial pemphigoid with stem cell failure. The viability of both "fresh" and frozen AM epithelial cells was assessed after storage.

Methods-AM was stored at either $+4^{\circ} \mathrm{C}$ ("fresh") or at $-80^{\circ} \mathrm{C}$ (frozen). A "fresh" graft was applied to the cornea following superficial keratectomy. Subsequently, a further frozen graft was applied to the same eye. Viability of the stored AM epithelium was assessed by investigating membrane integrity and mitochondrial activity.
\end{abstract}

Results-In both cases the cornea reepithelialised and visual acuity improved. Improvement, however, was not sustained.

Conclusion-Although both procedures led to an improvement in visual acuity, "fresh" tissue performed no better than frozen in promoting re-epithelialisation. The authors suggest that logistical, safety, and cost considerations outweigh any benefits of using "fresh" as opposed to frozen graft material.

(Br f Ophthalmol 2001;85:905-907)

Amniotic membrane has been used sporadically for many years in a variety of clinical applications. ${ }^{12}$ Recently, there has been a resurgence of interest in amniotic membrane transplantation for ocular surface reconstruction..$^{3-6}$ Various methods have been used to preserve amniotic membrane including "fresh" (or more appropriately hypothermic) storage, freezing, and freeze drying. ${ }^{7-9}$ Maintenance of the integrity of the basement membrane and stromal matrix appears to be central to promoting rapid re-epithelialisation, ${ }^{8}$ and storage conditions were chosen to optimise this.

We report the use of amniotic membrane grafts, both hypothermically stored (in CPTES + chondroitin sulphate ${ }^{10}$ and glycerolised frozen, ${ }^{8}$ in a case of severe pseudopemphigoid secondary to glaucoma therapy. In the absence of banked frozen amnion and because of the pressing nature of the patient's condition, it was decided to proceed initially using hypothermically stored tissue. A subsequent regraft utilised banked frozen amnion.

A low grade inflammatory response has been reported under conditions where viable amniotic epithelial cells are present. ${ }^{11}$ The viability of the amniotic membrane graft epithelial cells was therefore assessed for both hypothermically stored and frozen tissue after storage. This was done by investigating mitochondrial activity and cell membrane integrity.

\section{Patient and methods}

CLINICAL CONDITION

The patient was a 50 year old man with drug induced cicatricial pemphigoid with stem cell failure. Total corneal epithelial (stem cell) failure was confirmed by impression cytology which showed the presence of goblet cells and cytokeratin 19 (conjunctival epithelial phenotype) staining epithelial cells with an absence of any cytokeratin 3 staining (corneal epithelial phenotype) epithelium.

His disease followed 6 years of treatment with guanethidine and adrenaline eye drops for open angle glaucoma. The left eye was completely blind secondary to glaucoma, and the right eye had become blind due to a superficial corneal vascular membrane. The underlying corneal stroma was normal. Following superficial keratectomy and amnion grafting, the patient's vision improved, but then deteriorated again because of a recurrence of a thick neovascular pannus. The procedure was repeated, with a $360^{\circ}$ stem cell allograft.

DONOR SELECTION

Processing and testing of the tissue and microbiological screening of the donor required a 10 day lead time before elective surgery for the first, hypothermically stored "fresh" graft. For this reason, timing of the surgery and retrieval of the donated placenta were of crucial importance. A donor, due to undergo elective caesarean section 2 weeks before the proposed date of the eye surgery, was selected. A detailed medical and behavioural history together with signed consent was obtained from the donor. Serological tests were carried out by both enzyme linked immunosorbent assay (ELISA) and polymerase chain reaction (PCR). Exclusion criteria were consistent with those developed by the NBS for blood, tissue and cord 
blood donation. ${ }^{12}$ The same procedure was followed for the donor of the frozen tissue. Frozen tissue is banked for up to 12 months, and can be used after the initial 6 month quarantine period, which allows for mandatory postdonation retesting.

PROCESSING

The placenta was retrieved intact and processed under sterile conditions. The chorioamnion was stripped from the placenta and, following antibiotic decontamination, ${ }^{13}$ the amniotic membrane was separated from the chorion, cut into $2 \mathrm{~cm}$ squares and mounted on nitrocellulose backing paper. The grafts were then stored individually in sterile CPTES solution containing $2.5 \%$ chondroitin sulphate (CS) at $+4^{\circ} \mathrm{C}$. Amniotic membrane for the second graft was processed in a similar manner but stored frozen in a 50\% glycerol-Hanks's balanced salts solution at $-80^{\circ} \mathrm{C}$. Samples of both membranes were taken before and after processing for bacteriology and viability assays. The grafts were quarantined until results of the serological and bacteriological tests, the epithelial assessment, and the donor's medical history had been reviewed.

ASSESSMENT OF GRAFT EPITHELIUM

The viability of the AM epithelium was assessed by two methods: a fluorescent membrane integrity assay employing acridine orange/propidium iodide ( $\mathrm{AO} / \mathrm{PI})$ and a tetrazolium reductase assay of mitochondrial activity. ${ }^{14}{ }^{15}$ Mitochondrial activity was assessed on AM from three placentas including those used clinically. Microscopic evaluation using AO/PI was carried out after storage both at $+4^{\circ} \mathrm{C}$ and $-80^{\circ} \mathrm{C}$.

\section{Results and discussion}

In both cases, all serological and bacteriology results were negative. The hypothermically stored tissue was released for use within 12 days, while the frozen tissue was released after 6 months.

The assessment of the graft epithelium is shown in Figures 1 and 2. There were similar levels of mitochondrial activity in both hypothermically stored and frozen tissue, compared with heat treated non-viable controls. The results of the $\mathrm{AO} / \mathrm{PI}$ membrane integrity tests confirmed that the graft epithelia, stored by both methods, were non-viable.

Following superficial keratectomy, the "fresh" AM graft was transplanted onto the patient's right eye 14 days after retrieval of the placenta. Postoperative results were initially encouraging. Six weeks following the operation, the cornea had almost completely reepithelialised, giving a functional improvement in vision to $3 / 60$. However, although the epithelium was initially relatively clear, after 6 months the thick, neovascular, conjunctival derived membrane had recurred with a concomitant reduction in vision.

The procedure was repeated after 7 months using a frozen AM graft with a stem cell allograft. This epithelialised much faster and was healed in 3 weeks, with an improvement in

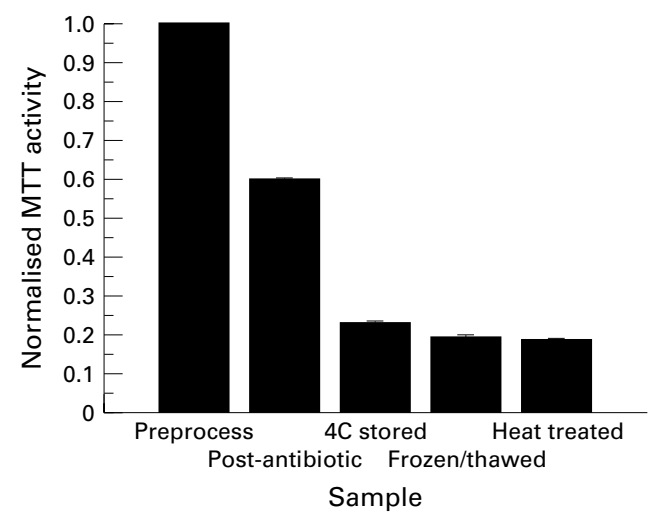

Figure 1 Tetrazolium reductase (MTT) activity in samples of amniotic membrane $\left(1 \mathrm{~cm}^{2}\right)$ at different stages of processing and storage. MTT activity is expressed as a fraction of the initial activity before processing $(n=3)$. All values are mean (SEM).

vision to $4 / 60$. Again, the improvement was not maintained, and the patient has since had a stem cell allograft from a living related donor, resulting in a clear corneal epithelial phenotype at the present time ( 2 months after surgery).

Amniotic membrane grafting, though becoming more widespread, is a low volume tissue product from the point of view of the tissue banks. Current practice dictates a short shelf life for frozen amnion, which inevitably leads to outdating and discard of some tissue. An alternative to this might be an "ondemand" service whereby amnion is procured and stored under hypothermic conditions for named patients as and when required.

There are however a number of clinical and practical difficulties in using hypothermically
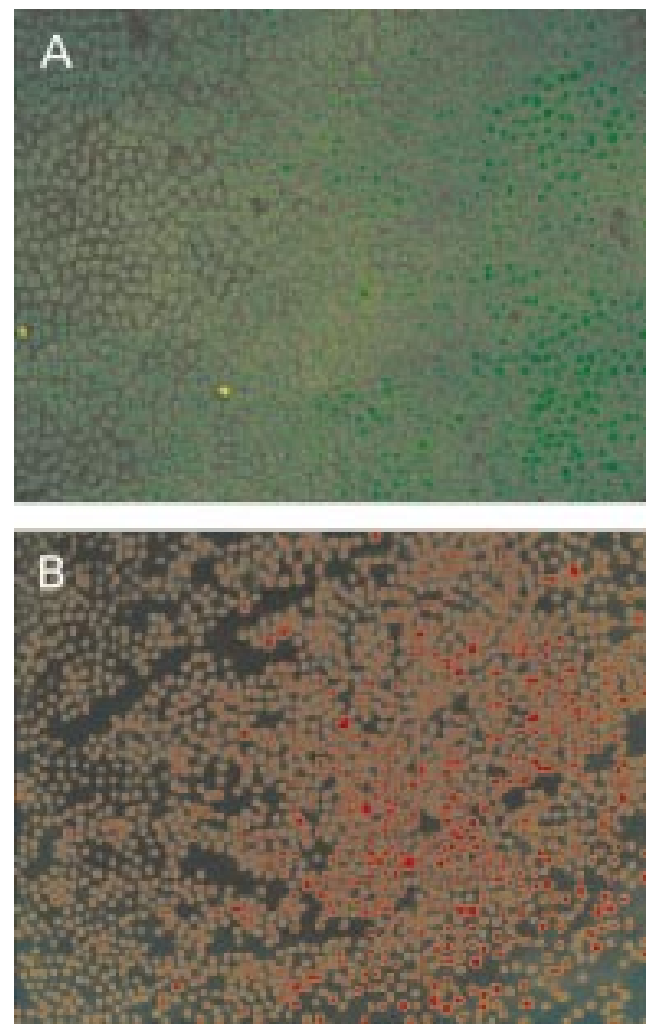

Figure $2 A O / P I$ of preprocess $(A)$ and post storage $(B)$ amnion showing epithelial cell layer. $(A)$ Cell membranes all apparently intact. (B) No viable cells visible. 
preserved membrane grafts compared with frozen material. The first, and most important of these, is a theoretical risk of disease transmission. Because of the short time between procurement and implantation, a serological retest of the donor is not possible. Though this risk was reduced both by careful donor screening and additional PCR testing for HIV-I and II and hepatitis C virus (HCV), a slight risk inevitably remains. Frozen storage of the tissue permits repeat blood testing of the donor 6 months following donation of the tissue, and effectively eliminates this risk.

The second difficulty was logistical: the need to find a suitable donor sufficiently far in advance of surgery to allow processing and testing, and coordination with the admission to hospital of the recipient. This does not arise with banked, frozen tissue.

The third drawback in using this method is that the grafts have to be prepared to order for a particular patient, the rest of the amniotic membrane being discarded. If the grafts are prepared for frozen storage, up to 30 can be prepared from one placenta giving much greater cost effectiveness.

The laboratory tests show that the graft epithelium was non-viable in both cases. The clinical results from this patient showed no obvious benefit in using "fresh" AM compared with the frozen material.

Though it is possible to produce hypothermically stored amniotic membrane grafts that appear to be comparable to frozen grafts both morphologically and clinically, it is our opinion that on safety, logistical, and cost grounds the disadvantages are likely to outweigh any benefits. The North London Tissue Bank has since instituted a rolling programme of frozen amnion banking which accepts the likely outdating of some grafts, but ensures a continuity of supply for the clinician.

1 Trelford JD, Trelford-Sauder M. The amnion in surgery, past and present. Am f Obstet Gynecol 1979;134:833-45.

2 Matthews RN, Faulk WP, Bennett JP. A review of the role of amniotic membranes in surgical practice. Obstet Gynaecol Апnи 1982;11:31-58.

3 Tseng SCG, Prabhasawat P, Barton K, et al. Amniotic membrane transplantation with or without limbal allografts stem cell deficiency. Arch Ophthalmol 1998;116:431-41.

4 Prabhasawat P, Barton K, Burkett G, et al. Comparison of conjunctival autografts, amniotic membrane grafts, and primary closure for pterygium excision. Ophthalmology 1997;104:974-85.

5 Azuaro-Blanco A, Pillai CT, Dua HS. Amniotic membrane transplantation for ocular surface reconstruction. $\mathrm{Br} F$ Ophthalmol 1999;83:399-402.

6 Shimazaki J, Shinozaki N, Tsubota K. Transplantation of amniotic membrane and limbal autograft for patients with
ambion recurrent pterygium associated with symblepharon. $\mathrm{Br} F$ Ophthalmol 1998;82:235-40.

7 Trelford-Sauder M, Trelford JD, Matolo NM. Replacement of the peritoneum with amnion following pelvic exenteration. Surg Gynecol Obstet 1977;145:699-701.

8 Lee SH, Tseng SC. Amniotic membrane transplantation for persistent epithelial defects with ulceration. Am $\mathcal{F}$ Ophthalmol 1997;123:303-12.

9 Ward DJ, Bennett JP, Burgos H, et al. The healing of chronic venous leg ulcers with prepared human amnion. Br f Plastic Surg 1989;42:463-7.

10 Taylor MJ, Hunt CJ, Madden PW. Hypothermic preservation of corneas in a hyperkalaemic solution (CPTES): 2. Extended storage in the presence of chondroitin sulphate. Br f Ophthalmol 1989;73:792-802.

11 Akle CA, Adinolfi M, Welsh KI, et al. Immunogenicity of human amniotic epithelial cells after transplantation into

12 Guidelines for the Blood Transfusion Services in the United Kingdom. 4th ed. London: Stationery Office, 2000.

13 Hunt CJ, Caffrey EA, Large SR. Factors affecting the yield of cardiac valve allografts from living unrelated donors. Eur of cardiac valve allografts from living

14 Jones KH, Senft JA. An improved method to determine cell viability by simultaneous staining with fluorescein diacetate-propidium iodide. $\mathcal{F}$ Histochem Cytochem 1985; 33:77-9.

15 Denizot F, Lang R. Rapid colorimetric assay for cell growth and survival: modifications to the tetrazolium dye procedure giving improved sensitivity and reliability. $\mathcal{F}$ Immunol Methods 1986;89:271-7. 